\title{
Neurocristic Cutaneous Hamartoma of the Scalp
}

\author{
Sue Kyung Kim, M.D., You Chan Kim, M.D. \\ Department of Dermatology, Ajou University School of Medicine, Suwon, Korea
}

Neurocristic cutaneous hamartomas $(\mathrm{NCH}$ ) result from aberrant development of the neuromesenchyme. In addition to a dermal melanocytic component, these tumors can contain neuro sustentacular and fibrogenic components. The clinical importance of these lesions includes the potential for misdiagnosis as well as the development of malignant melanomas over a poorly described period of time. We present a rare case of $\mathrm{NCH}$ of the scalp in a 1-year-old female. (Ann Dermatol 21(4) 396 398, 2009)

\section{-Keywords-}

Hamartoma, Neurocristic, Scalp

\section{INTRODUCTION}

Neurocristic hamartomas $(\mathrm{NCH})$ result from the aberrant development of cells derived from the neural crest. This abnormality was first described by Tuthill et al. ${ }^{1}$ in 1982 and referred to as a pilar neurocristic hamartoma ${ }^{1-3}$. Neural crest-derived cells show fibrogenic, melanogenic, and neurosustentacular differentiation, and contribute to the formation and development of the local mesenchyme, especially in the cephalic regions ${ }^{3}$. The importance of the recognition of a $\mathrm{NCH}$ is due to the possible transformation to a malignant melanoma of the pigmented lesions over an unpredictable period of time ${ }^{4}$. We report a patient that presented with a blue-gray alopecic plaque on the scalp with the histopathological features of a $\mathrm{NCH}$.

Received March 17, 2009, Revised April 4, 2009, Accepted for publication April 21, 2009

Reprint request to: You Chan Kim, M.D., Department of Dermatology, Ajou University School of Medicine, 5, Woncheon-dong, Yeongtonggu, Suwon 443-721, Korea. Tel: 82-31-219-5190, Fax: 82-31-2195189, E-mail: maychan@ajou.ac.kr

\section{CASE REPORT}

A 1-year-old female presented with an asymptomatic alopecic plaque that was present since birth on the scalp. Physical examination showed a $3 \times 2 \mathrm{~cm}$ blue-gray plaque on the scalp with focal alopecia (Fig. 1). We initially suspected a blue nevus and performed a skin biopsy. The biopsy specimen revealed proliferation of nerve-like structures, spindle cells, and melanocytes. High power microscopic views showed fascicles of spindled cells and heavily pigmented cells with dendritic morphology (Fig. 2). Immunohistochemical staining showed diffuse S-100 protein staining within nerve-like structures and pigmented cells that extended to the deep dermis. HMB-45 also diffusely stained the pigmented cells; however, the area with schwannian differentiation did not stain with HMB-45. The stromal cells throughout the lesion were diffusely stained with CD34. NSE stained within the nerve-like structures. Magnetic resonance imaging showed a focal enhancing lesion in the deep soft tissue of the scalp. However, there was no evidence of abnormalities in the cortex of the brain. Because the patient was too young at the time of the initial evaluation surgical excision was planned for later.

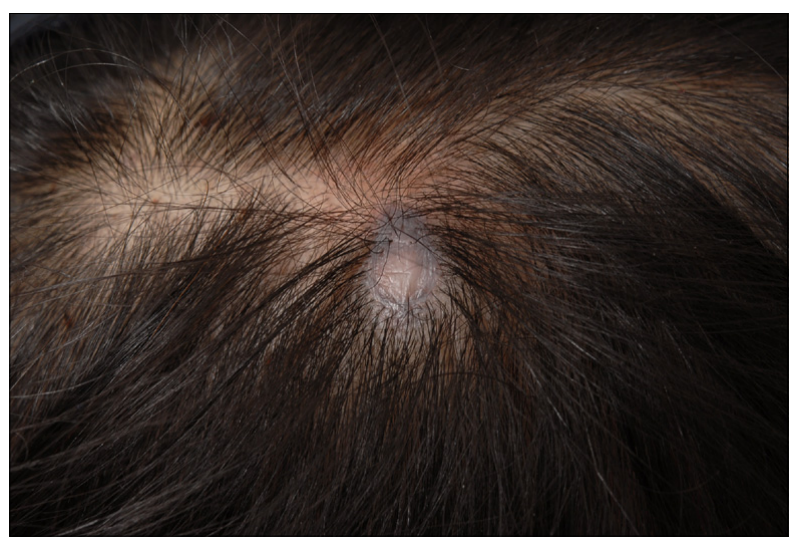

Fig. 1. $3 \times 2 \mathrm{~cm}$ blue-gray plaque on the scalp. 

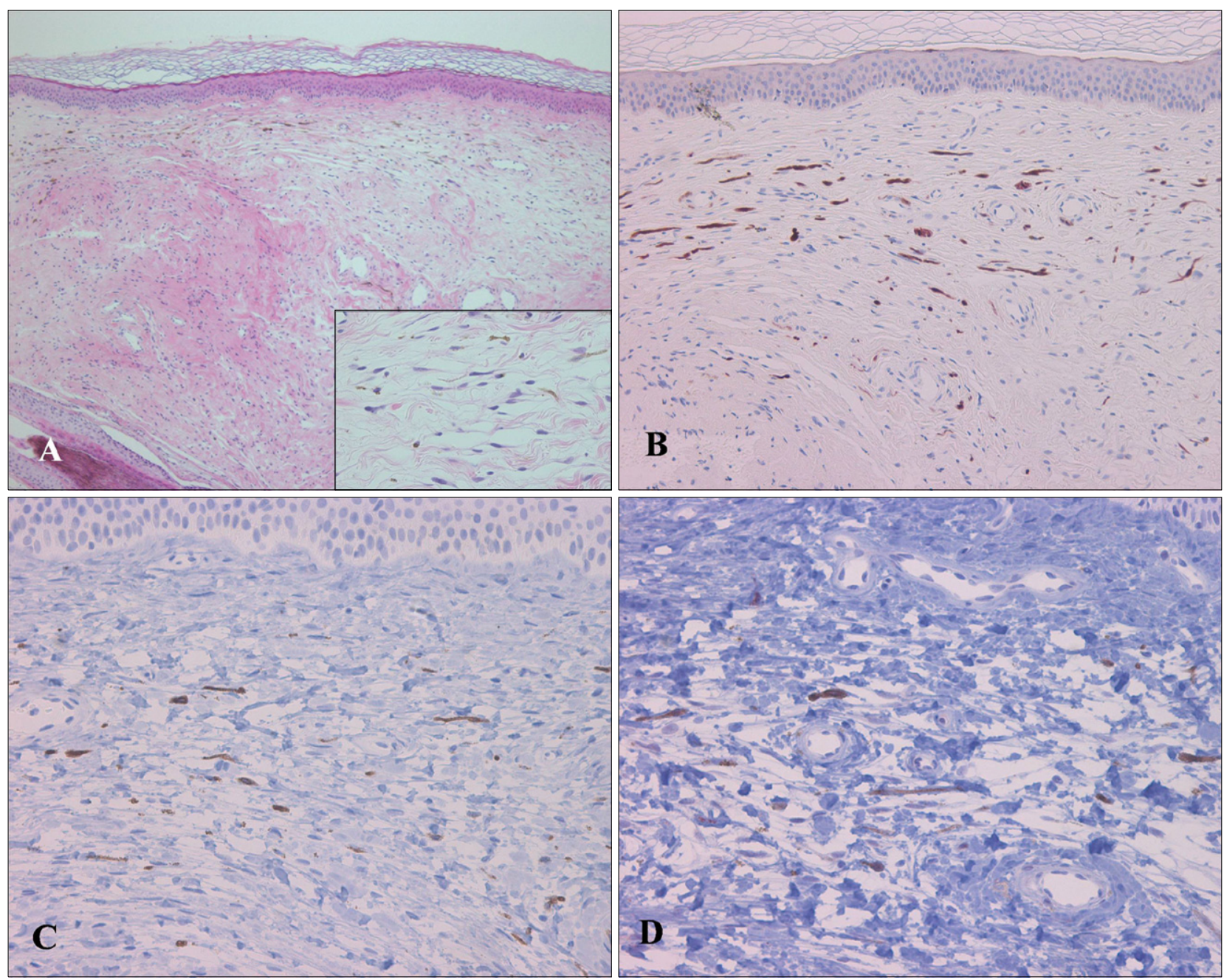

Fig. 2. (A) Proliferation of nerve-like structures, spindle cells, and melanocytes (H\&E, $\times 100)$ (inset, wavy spindle cells, $\times 400)$. (B) Diffuse S-100 protein staining within the nerve-like structures and pigmented cells (Immunohistochemical staining using the ABC method, $\times 200$ ). (C) HMB-45 diffusely stained the pigmented cells, however, the area with schwannian differentiation did not stain with HMB-45 (Immunohistochemical staining using the ABC method, $\times 400$ ). (D) NSE staining within the nerve-like structures (Immunohistochemical staining using the $A B C$ method, $\times 400$ ).

\section{DISCUSSION}

Several cases of $\mathrm{NCHs}$ have been reported previously $^{1,2,4-11}$. In the Korean dermatologic literature, a case of dermal melanocytosis on the trunk with features of neurocristic cutaneous hamartoma has been reported ${ }^{12}$. The dermal melanocytoses include a variety of pigmented lesions that are formed from the aberrant development of neural crest-derived melanocytes as they migrate through the dermis during embryogenesis ${ }^{5}$. $\mathrm{NCH}$ is one type of dermal melanocytosis. $\mathrm{NCH}$ is composed of melanocytes that are confined to the dermis and sometimes the subcutaneous tissue with a neural crest-derived Schwann cell component ${ }^{5}$. Clinically and histopathologically, the features of $\mathrm{NCH}$ s overlap with other dermal melanocytoses, especially the blue nevus. The clinical features in this case resembled the plaque-type blue nevus. However, NCHs have a predilection for the scalp with focal alopecia and generally are not found on the trunk. Histologically, $\mathrm{NCH}$ lesions are composed of dermal melanocytes and neuroidal structures with schwannian differentiation. $\mathrm{NCH}$ lesions usually stain with CD34 and have a decreased number of hair follicles ${ }^{5}$. However, blue nevus lesions usually are not stained with CD34 and the number of hair follicles with a blue nevus are not decreased ${ }^{9}$. Other reported features of $\mathrm{NCH}$ include melanocytes distributed around hair follicles, eccrine glands, vessels and nerves, involvement of the subcutaneous tissue, and the presence of tactoid bodies $^{1,2,9-11}$. In our case, we also noted proliferation of dermal melanocytes and neuroidal structures with sch- 
wannian differentiation. The immunohistochemical staining with S-100 protein, HMB-45, CD34, and NSE confirmed the diagnosis.

Although only a few cases have been reported, a significant number of these cases have shown development of a malignant melanocytic component ${ }^{2,10}$. Melanomas have developed within 1 6 years from the initial diagnosis of $\mathrm{NCH}$. However, melanomas developing from congenital $\mathrm{NCH}$ lesions have been identified 15 67 years after birth ${ }^{2}$. Because of the unpredictable development of a malignancy, long-term follow up with cancer surveillance is generally recommended in patients with $\mathrm{NCH}^{2,13}$. Complete surgical resection of the lesion likely prevents the development of a melanoma.

In summary, we describe a rare case of $\mathrm{NCH}$ of the scalp with alopecia. Dermatologists should consider $\mathrm{NCH}$ in the differential diagnosis of a blue-gray alopecic plaque on the scalp. Early diagnosis is useful for the proper management of $\mathrm{NCH}$ including surveillance for the development of a malignant melanoma.

\section{REFERENCES}

1. Tuthill RJ, Clark WH Jr, Levene A. Pilar neurocristic hamartoma: its relationship to blue nevus and equine melanotic disease. Arch Dermatol 1982;118:592-596.

2. Pearson JP, Weiss SW, Headington JT. Cutaneous malignant melanotic neurocristic tumors arising in neurocristic hamartomas. A melanocytic tumor morphologically and biologically distinct from common melanoma. Am J Surg Pathol 1996;20:665-677.

3. Reed RJ. Neuromesenchyme. The concept of a neurocristic effector cell for dermal mesenchyme. Am J Dermatopathol 1983;5:385-395.

4. Denlinger CE, Slingluff CL Jr, Mihm MC Jr, Patterson JW. Extensive neurocristic hamartoma with skeletal muscle involvement. J Cutan Pathol 2007;34:634-639.

5. Bevona C, Tannous Z, Tsao H. Dermal melanocytic proliferation with features of a plaque-type blue nevus and neurocristic hamartoma. J Am Acad Dermatol 2003;49:924-929.

6. Crowson AN, Magro $\mathrm{CH}$, Clark WH. Pilar neurocristic hamartoma. J Am Acad Dermatol 1996;34:715.

7. Karamitopoulou-Diamantis E, Paredes B, Vajtai I. Cutaneous neurocristic hamartoma with blue naevus-like features and plexiform dermal hyperneury. Histopathology 2006;49:326328.

8. Kikuchi I, Inoue S, Taketomi I, Ono T. Two cases of nevus fuscocaeruleus with pain, including a case of pilar neurocristic hamartoma. J Dermatol 1983;10:275-280.

9. Mezebish D, Smith K, Williams J, Menon P, Crittenden J, Skelton $\mathrm{H}$. Neurocristic cutaneous hamartoma: a distinctive dermal melanocytosis with an unknown malignant potential. Mod Pathol 1998;11:573-578.

10. Pathy AL, Helm TN, Elston D, Bergfeld WF, Tuthill RJ. Malignant melanoma arising in a blue nevus with features of pilar neurocristic hamartoma. J Cutan Pathol 1993;20:459464.

11. Smith KJ, Mezebish D, Williams J, Elgart ML, Skelton HG. The spectrum of neurocristic cutaneous hamartoma: clinicopathologic and immunohistochemical study of three cases. Ann Diagn Pathol 1998;2:213-223.

12. Jin WW, Jung KE, Park JW, Kim MH. A case of dermal melanocytosis with features of neurocristic cutaneous hamartoma. Korean J Dermatol 2008;46:1245-1248.

13. Goldenhersh MA, Savin RC, Barnhill RL, Stenn KS. Malignant blue nevus. Case report and literature review. J Am Acad Dermatol 1988;19:712-722. 